\title{
Comparing Motivations for including enforcement in U.S. COVID-19 State Executive Orders.
}

\section{Authors:}

\section{Cali Curley, PhD}

Department of Political Science

University of Miami

cac561@miami.edu

https://orcid.org/0000-0003-3244-2623

Nicky Harrison, MPA

nickycharrison@gmail.com

O’Neill School of Public and Environmental Affairs

Indiana University Purdue University Indianapolis

Peter Federman, PhD

federman@iu.edu

O’Neill School of Public and Environmental Affairs

Indiana University Purdue University Indianapolis

https://orcid.org/0000-0003-4272-6961

This is the author's manuscript of the work published in final edited form as:

Curley, C., Harrison, N., \& Federman, P. (2021). Comparing Motivations for Including Enforcement in US COVID-19 State Executive Orders. Journal of Comparative Policy Analysis: Research and Practice, 23(2), 191-203. https://doi.org/10.1080/13876988.2021.1880871 


\title{
Comparing Motivations for Including Enforcement in U.S. COVID-19 State Executive Orders.
}

\begin{abstract}
:
The United States' response to COVID-19 has been predominantly led by state governments. To understand if, why, and how state governments include enforcement language in their executive order response, we conduct an analysis based on 1,357 coded executive orders. We find that decisions to include enforcement language are influenced by a governor's political circumstances and perceived risks associated with the crisis. This paper offers insight into how these findings are important for future research and an explanation of the distinct ways that U.S. state governments are choosing to address COVID-19.
\end{abstract}

Keywords:

Enforcement, COVID-19, Policy Design, Compliance 


\section{Comparing Motivations for Including Enforcement in U.S. COVID-19 State Executive Orders.}

\section{Introduction}

During the COVID-19 pandemic, a series of policies including wearing masks, staying home, social distancing, quarantining when sick, and getting tested have been put into place (CDC 2020; Cohen and Kupferschmidt 2020; Fowler et al. 2020). However, in some cases these actions and their public adoption (i.e., mask wearing) have been linked to political ideology (Makridis and Rothwell 2020), which when paired with distrust in the scientific community (Klofstad et al. 2019) may limit the ability of the government to rely solely on voluntary compliance (Curley and Swann 2018). The design of policy varies substantially, particularly with respect to emphasis placed on including enforcement (Curley and Federman 2020). In the absence of federal action in the United States, (Bowman and McKenzie 2020) state governors have largely led the response to COVID-19; state-level executive orders have proliferated with haste and wide degrees of variation (Curley and Federman 2020).

Existing literature on enforcement emphasizes the enforcement of a policy (May and Winter 2011), not the factors that motivate enforcement in policy design. This paper addresses this gap by exploring determinants that shape the use of enforcement language in state executive orders during the United States response to COVID-19. The purpose of this comparison is to increase the internal validity of this research (Radin and Weimer 2018). Given that little empirical work has explored the determinants of enforcement-oriented policy design, we answer the question: what factors influence the decision of a U.S. state government to include enforcement mechanisms within their executive orders in response to COVID-19? To answer this question, 1,357 U.S. state executive orders, spanning January through May 2020, have been coded and analyzed. This work has implications for how we understand the United States COVID-19 state level policy response during the initial closures and enables future research to explore the implications of this enforcement design choice on policy outcomes.

In the next section, we provide context into the U.S. COVID-19 policy response insight. We then proceed to outline two frames explaining why enforcement language is included by some governors: 1) political self-interest and 2) perceived risks. Following this we describe our data, modeling, and results. We offer a series of conclusions and avenues for future research related to this avenue of study.

\section{Executive Order Context}


To fight COVID-19, a range of executive orders were signed into effect by the U.S. Governors including public health policies meant to restrict the movements of the public (Gostin and Wiley 2020). These policies included stay-at-home orders, business closures, restaurant closures, capacity limits, gathering bans, travel quarantines, etc. Many of these orders have been explored in policy analysis as primarily binary, not allowing for much variation in the content of these orders. Recent research provides conflicting evidence about the value of stay-at-home orders, which suggests there may be something that existing research is missing. Scholars have suggested that a binary understanding of COVID-19 orders is a relatively reductive approach to understanding the content of these orders (Curley and Federman, 2020). Some of these orders have largely relied on voluntary compliance without containing much of a formal sanction or mandate within them

In the U.S., response executive orders were commonly used to increase power of the governor and control over their administration (Ferguson and Bowling, 2008). The use of executive orders as emergency powers in times of crisis have been reviewed by law scholars, with hesitancy and fear about overreach on the part of governors (Tyler 2008). While Gubernatorial power to issue executive orders varies across states (Council of State Government 2004), most of the COVID-19 executive orders draw powers issued from the declaration of an emergency. Across 49 states during the year 2004-5, 3,456 executive orders had been adopted (Ferguson and Bowling, 2008). These are a relatively common policy creation tool at the state level, particularly in times of crisis.

As an element of policy design sanctions or enforcement language serve an important role in understanding the proposed burdens and benefits anticipated from a particular policy. However, sanctions and the motives for their inclusion remain understudied (Siddiki et al., 2019). Typically, the concept of enforcement has been studied in terms of how rules are enforced (May and Winter 2011), not necessarily the motives behind designing the rules. However, some work exists that explores the range of potential mechanisms that can be used as sanctions. Holley et al (2020:416) provides a list of mechanisms for designing enforcement, while Aryes and Braithwaite (1992) put together a pyramid of potential actions that increase in stringency.

In a qualitative exploration of enforcement language included in these orders we discovered that sanctions largely included jail time, fines, and permitting consequences. Out of over 1300 executive orders related to COVID-19 from February to May there were roughly 180 orders that included enforcement language that embedded some form of sanction for noncompliance. This includes a wide range of orders that included enforcement including gathering bans, travel quarantines, business closures, capacity limits, school closures, and stay-at-home orders that often-had multiple targets of enforcement but included business closures and gathering bans. Enforcement language includes a wide range of statements that include terms like violation, punishment, compliance, enforcement, imposed, and penalized. These orders 
require compliance to be deemed effective; compliance may be encouraged when there are sanctions in place to punish non-compliance. However, given the politicization of the pandemic, compliance has become a political statement rather than a necessary response to a deadly virus. This has been seen in the use of masks (Lyu and Wehby, 2020), the adoption of stay-at-home orders (Corder, Mingus, and Blinova 2020), and even the speed with which states responded to the pandemic (Fowler, Kettler, and Witt 2020). Despite the politicization of these policies, compliance is a necessary condition for these orders to work, which means that enforcement mechanisms may be adopted to alter the costs associated with non-compliance. Given the emphasis of existing research on the politicization of the COVID-19 response in the U.S., it is likely that decisions to include sanction or enforcement language may be dictated by the political self-interest and perceived risks of the decision maker.

\section{Theoretical Framing:}

In this section two concepts political self-interest and perceived risk are outlined. Both concepts should influence governor decisions to include enforcement language in their executive orders. Following the discussion of these frames, we detail our data, variables that operationalize these theoretical framings, conduct our analysis, and discuss our findings are related to the political and risk related frames as described in this section.

\section{Political Self-Interest}

Research on the U.S. political system suggests that Democratic or liberal-leaning officials are more likely to support enforcement (Mete 2002), particularly on environmental issues (Innes and Mitra 2015). This may be due to the long-standing assumption that Democrats are considered pro-regulation and Republicans anti-regulation (Teske 2004). As enforcement may potentially be costly, these choices may also be related to differing perspectives on government spending, understanding that Republicans typically take a more fiscally conservative stance (Mete 2002). Despite the underlying motivation, if it is true that Democrats are more likely to support enforcement, then it follows that they may be more likely to pen policies with embedded enforcement mechanisms. Previous research suggests that individuals and firms are more likely to increase compliance levels when there are Democrats in positions of power (Mete 2002). This establishes the first frame, that the presence of enforcement language is largely political, and will be more likely under a Democratic governor and less likely under a Republican governor.

The politicization of the pandemic has been particularly evident in the delaying of lockdowns and stay-at-home orders, with Democratic governors being viewed as more quickly to respond (Fowler, Kettler, and Witt 2020). In addition to stay-at-home orders, other policies have been politicized including mask wearing (Halpern 2020). The current response of the U.S. to COVID-19 has been termed "pandemic politics" and has as largely emphasized the role of party affiliation in the U.S. context. (Solano et al., 2020). While this may be the case, there are other 
elements related to political motives that might prove relevant to the inclusion of enforcement language. Reelection also poses an important political element that shapes the types of policies that politicians pursue (Pulejo and Querubin, 2020). Being up for reelection is one element that is important to how governors make decisions, but the public's party affiliation and commitment to that party affiliation is also relevant in considering a bid for reelection and public support for specific policy actions.

\section{Perceived Risk}

Beyond political motives, governors may be motivated to act by a commitment to the public good. How governors perceive risks associated with a particular problem might influence their willingness to adopt certain policies (Somers \& Svara 2009), and/or potentially increase the stringency of those policies. While research related to governor risk perceptions is limited, emergency managers have been shown to have different perspectives of risk based on their income or education. Research suggests that female managers are more likely to perceive risk accurately and with more concern about potential negative outcomes (Peerbolte \& Collins 2013).

We do know that states are more likely to adopt policy when experiencing high levels of a problem or vulnerability to the problem (Rai 2020). Research on COVID-19 suggests that people of color (Wright and Merritt 2020), the elderly (Zheng et al. 2020), and men (Griffith et al. 2020) are considered at risk of severe disease outcomes such as hospitalization. In addition, governors may perceive hospitalizations, infection rates, and positive cases as indicators of the severity of COVID-19. Asymptomatic spread and associated cases complicate the accuracy of current measures that gauge the severity of the pandemic (Gandhi, Yokoe, Havlir, 2020).

People perceive their own risk in nuanced and layered ways, and it has been suggested that the way populations perceive of their own risk may be associated with the policy choices leaders make (Kam \& Simas 2010 Given that people infer their own risk in varied ways, it would follow that compliance levels of the public would also vary, the predictions of compliance levels might influence the choice to lean on voluntary compliance (Curley and Swann, 2018). If a governor perceived compliance levels to be high, they may be less likely to rely on formal sanctions. Research related to this idea suggests that women are more likely to comply with these types of mandates than men (Zajenkowski et al. 2020). Other characteristics such as age, education, political ideology, and income, may also impact risk taking (Kam \& Simas 2010).

\section{Data and Methods}

The data used in this paper stems from systematic coding of state-level executive orders adopted in response to the COVID-19 pandemic from February to May 2020. The orders were 
hand coded (Bennett and Checkel 2015). Given the choice of this document review and coding strategy, each executive order was read and coded by at least two individuals, providing an increase in inter-coder reliability, and building code agreement.

The first step in our coding process was to search for and collect executive orders released in each state. The individuals coding then developed a database from the executive orders that captured how the executive orders were changing over time by developing panel data for each state. Given that this process is iterative, the coders captured initial variables based on popularized policy changes but expanded as each order yielded additional information. The focus was to qualitatively capture the text related to each 'category' identified in the initial coding process, which led to the statements around enforcement being gathered through the initial process tracing strategy. We conducted a second robustness check on our coding for enforcement language on the orders adopted from January through April for all 50 states using keywords (i.e., violation, punishment, penalty, enforcement, impose, compliance). Our original data collection correctly identified $75 \%$ of observations where enforcement was present.

Other data gathered for the purpose of this analysis includes state level demographic data (i.e., age, median income, race, gender) from the 2019 population estimates conducted by the U.S. Census Bureau (United States Census Bureau 2019); the governors information comes from government websites from each of the 50 states; and information on party affiliation comes from a 2017 Gallup Poll (Gallup 2017). We also utilize confirmed COVID-19 cases released from USAFacts.org (USA Facts 2020). Future iterations of this data might also include changes to mobility, as this indicator has been utilized in several projects that examine the impacts of policy efforts to slow the spread of COVID-19 (Yilmazkuday 2020), particularly during this time period as data on testing, hospitalizations, and death have issues inherent in reporting (Bauchner et al. 2020).

This analysis explores decisions to include enforcement language within executive orders. While many comparative policy analysis studies have taken a qualitative and/or case study approach (Agranoff and Rubin 1991), here we utilize quantitative analysis to determine indicators of enforcement language. This methodological choice allows for a close empirical comparison of sub-national governments and is made possible by the fact that much of the cultural and constitutional elements are constants, given the adherence of all to norms and laws of the United States. Further, this inter-state approach allows for relevant comparison between similar political systems, as each of the states is bound by the Constitution to a republican form of government (Radin and Weimer 2018).

The dependent variable is binary, where the observation takes a value of one if the executive order includes enforcement language and a value of zero if it does not. Given that there are 187/1361 orders that include enforcement language and there is no hard/fast rule for when rare events bias coefficients in binary dependent variable analysis, we conduct a series of analyses, probit, logit, and firth logits to test the stability of our findings, given the potential for a rare events bias in the data. The firth logit model is commonly used when seeking to predict binary outcomes that are unbalanced, meaning there is a small number of outcomes with values 
equal to 1, this is supposed to reduce "bias in the maximum likelihood estimates of coefficients" (Puhr et al. 2017, pg. 1). The findings in terms of their significance and directionality are consistent across model specifications. This suggests that our models, despite the penalty in the firth logit, may not require its inclusion. Results between logistic and probit analysis tend to be similar (Zelner 2009), we choose to report the probit models because of ease of interpretability.

The models will include a series of independent variables referring to political motives present in enforcement decisions, operationalized through governor's party affiliation, reelection information, and tenure. We also include a variable termed competitive politics which refers to the potential of a state to swing between the parties. Gallup data classifies this as a 'competitive' state, meaning that the aggregate voter registration allows for a state to sway between Republican (conservative) and Democrat (liberal) representatives with more ease. More specifically, a competitive state is one in which one party has less than a five percentage-point advantage in registered voters over the other. This variable is operationalized to demonstrate the potential need of governors to appeal to voters on both sides to stay in office, therefore competitive politics takes on a value of one if the state is considered competitive by Gallup, and a zero otherwise.

The second set of variables relate to perceived risk of the COVID-19 outbreak, operationalized by gender of the governor (impacts valuation of risk), potential at-risk groups (percentage of minority and individuals over 65) (impacts expected case severity), the percentage of women in that state (impacts expectations of compliance), and lagged cases (characterize the status of the outbreak). Lagged cases are operationalized as a 1-day lag on the reported positive case rate in the state. Given the rapid proliferation of executive orders at this time and the lack of accurate and reliable metrics on outbreak severity available to decision makers during the early months of the pandemic (i.e., complete absence of or low access to testing), while we include positive cases in the model it is not expected that this played a large role in decision making this early in the public health crisis. Lastly, we include a series of potential control variables such as the state's capacity to enforce, operationalized by the education level, income levels, and responsiveness of the public operationalized by party affiliation of registered voters. These concepts for state level capacity to enforce are drawn from research conducted by Schwartz (2003) on factors that lead to increased enforcement capacity.

Several independent variables that represent policies are included in the analysis as well. This data is collected from the executive orders and is primarily captured as binary, where the item takes a value of 1 if the directive is mentioned. There are two variables that are rated according to stringency of the directive: gathering bans and travel quarantines. Gathering bans are scored based on how strict the ban is, with a value of 1 representing a gathering ban on at least 1,000 people and proceeding until a score of 8 represents a stated ban on gatherings outside of the immediate family. The travel quarantine takes a value of 1 if there is any limited (typically by geography) requirement for a two-week quarantine for out of state travel, and a value of 2 if it is an inclusive two-week quarantine requirement for all travelers. Table 1 below provides additional insight into the summary statistics. 
[Insert Table 1 about here]

\section{Findings}

Four different model specifications are used to determine the stability of the findings. The first model presented depicts the full model with state clustered standard errors. The second model presents the controls specific to the orders, this also includes a state clustered standard error even though all variables are at the order level. The data includes the entire range of potential orders (i.e., declaring a state emergency, rule suspensions, etc.), so the chosen control variables are those that are more often linked with activities that may lead to enforcement. The second model presented here consists of the variables that make up our two framings without controls these are measured at the state-level, the analysis includes state clustered standard errors. According to existing research clustering of standard errors is one of many other acceptable approaches to handling nested data as is present in this case (Huang, 2016). The results from the analysis are presented in Table 2 and discussed below.

[Insert Table 2 About Here]

\section{Political Self-Interest}

The probit analysis provides us with insight as to what factors increase the likelihood of an order including enforcement language. Supportive of our political self-interest framing, Republican governors are consistently found to be less likely than governors of other parties to include enforcement mechanisms in their executive orders. Some of our other politically related variables are also salient, the analysis suggests that a governor's political circumstances influence the decision to include enforcement language in the executive order directives. A competitive political environment increases the probability of enforcement, this suggests that in states where voters do not strictly follow party registrations governors are more likely to include enforcement language. In addition, it appears that a governor being further away from reelection decreases the probability of including enforcement language. These findings suggest that the inclusion of enforcement is political in nature, that it is more likely to occur in states that are politically competitive, helmed by Democrats, and with newer governors.

\section{Perceived Risk}

Risk perception influences governor decisions about the inclusion of enforcement language. Many of these variables are insignificant in the current modeling strategy. However, when not controlling for the order type, it appears that the more individuals within a state that are white, the less likely the state is to establish an executive order with an enforcement mechanism. This is a potentially concerning finding that requires additional exploration. One potential explanation, consistent with risk-related motivations, is that COVID-19 is impacting minority 
communities at higher rates than non-minority communities, meaning that having an increased presence of at-risk groups a governor adopts order types more frequently linked to enforcement language. However, for this to be true, we might anticipate that states with higher percentages of individuals over the age of 65 would also be more likely to adopt enforcement directives. One concerning explanation is that governors may perceive minority communities as less likely to voluntarily comply with mandates, this poses extremely significant and important directions for future research. Therefore, the inclusion of enforcement language, if linked to expectation of compliance, has extraordinary important social justice and equity implications that warrant further research.

The analysis presented here suggests that enforcement language is more likely when orders relate to gathering bans, travel quarantines, outdoor recreation, and stay at home orders are issued; there is limited support for entertainment venue closures and daycare closures increasing the inclusion of enforcement language. As a note of caveat, these state orders may be enhanced by local government action that creates their own enforcement of directives or closures in addition to those at the state level. The variation across order directives and the presence of enforcement language suggests that a deeper dive into what enforcement looks like in practice, rather than gubernatorial intent is necessary.

Lastly, we included the female governor variable in the model because there has been a debate about the differences in male and female leadership's response to crises like the pandemic. This analysis suggests that by themselves female governors are perhaps no different in their political motivations to the adoption of enforcement language; however, given the limited number of female governors and the inclusion of state-level clusters this finding may be questionable. Other research has found that female leaders have had different responses to the pandemic than male leaders (Aldrich and Lotito 2020) and this should continue to be explored given the limitations of our current analysis.

\section{Conclusion:}

The inclusion of sanctions and enforcement language in response to COVID-19 among U.S. states is politically motivated. We see strong and consistent evidence for political affiliation and the competitiveness of state politics as a motivating factor in enforcement decisions. This means that future research on enforcement should strongly consider the political culture of specific environments. We have seen evidence from studies around the world that suggest governments face difficulties in encouraging compliance due to the costs of monitoring and enforcement (Ramirez de la Cruz et al. 2020), which is particularly more difficult under the politicization of a pandemic. It is important to consider how cultural and political context may inform these elements -- particularly if the ability to enforce is political. There is some evidence that enforcement language may be responsive to public demands, both in terms of the political implications but also the demands of the public as evidenced by the repeal of enforcement language regarding Indiana's mask mandate (Lange 2020). The default for many U.S. governor 
led executive orders is to rely on voluntary compliance, which is largely influenced by individual motives (Curley and Swann, 2018).

This work builds on previous research that suggests the unique nature of politics in the United States can be relevant in a comparative context, and that the fragmentation of the political system in that country is the "point of departure" for federalism (Radin and Boase 2000). Given that we know the importance of party ideology for executives and the critical need for a comparative approach to public administration, this research furthers the goal of developing theory and method to understand the unique role executive orders play in the distribution and execution of administrative power (Van de Walle and Brans 2017). Radin and Weimer (2018) call on scholars to produce "research that makes comparisons across sub-national government... [since that] by holding national constitutional and some aspects of culture constant, they offer the possibility of more confident inferences about policy impacts (p. 69)." This work speaks to that behest and provides a starting point for further comparative work on enforcement.

This paper faces limitations including the accuracy of testing data as well as the capacity of testing. The data focuses on the initial round of closures which does not include questions of legitimacy regarding enforcement language raised by legislatures regarding the scope of executive orders in emergency and in some cases describe the inclusion of enforcement language as an overreach of gubernatorial power. This article only captures the governor's intent to allow enforcement not actual enforcement of the orders. In addition, the analysis would be enhanced with multi-level modeling, a longer timeline, and data on actual enforcement. Additional variables such as regionality can be included, the south has a long-standing history of disenfranchisement, racism, and the carceral state (Soss et al. 2008), which may contribute to some of the findings.

Future research should work to gather orders and directives at the local level related to local decisions to enforce state directives. To gauge the effectiveness of public health responses to the pandemic it will be necessary to identify data that captures the ability to enforce and the dollars spent on compliance enforcers, fines, and arrests to determine the degree to which the penalties were implemented. While state and local government budgets are stretched, implementing costly enforcement policy that requires high monitoring costs may decrease available resources for other important policies to curb the public health and social costs associated with the COVID-19 outbreak. Therefore, the motives for or against enforcement may prove important to understanding how communities address outbreaks in the future. Given that enforcement language adopted in executive orders appears to be politically motivated it is important to determine if enforcement changes public health outcomes.

\section{References:}


Agranoff, R. and Radin, B.A., 1991. The comparative case study approach in public administration. Research in public administration, 1(1), pp.203-231.

Aldrich, Andrea S., and Nicholas J. Lotito. "Pandemic Performance: Women Leaders in the Covid-19 Crisis." Politics \& Gender (2020): 1-9.

Alon, I., Farrell, M. and Li, S., 2020, Regime Type and COVID-19 Response. FIIB Business Review, p.2319714520928884, https://doi.org/10.1177\%2F2319714520928884.

Amat, F., Arenas, A., Falcó-Gimeno, A. and Muñoz, J., 2020, Pandemics meet democracy. Experimental evidence from the COVID-19 crisis in Spain. $O S F$, https://osf.io/dkusw/download.

Ayres, I., and Braithwaite, J. 1992, Responsive regulation. (New York: Oxford University Press).

Balla, Steven J. 2001, Interstate Professional Associations and the Diffusion of Policy Innovations. American Politics Research 29: 221-45. https://doi.org/10.1177/1532673X01293001

Bauchner, H., Golub, R.M. and Zylke, J., 2020, Editorial concern-possible reporting of the same patients with COVID-19 in different reports. Jama, 323(13), pp.1256-1256.

Bennett, A. and Checkel, J.T., 2015, Process tracing (Cambridge: Cambridge University Press).

Benson, D. and Jordan, A., 2011. What have we learned from policy transfer research? Dolowitz and Marsh revisited. Political studies review, 9(3), pp.366-378. https://doi.org/10.1111/j.1478-9302.2011.00240.x

Bowman AO, McKenzie JH, 2020. Managing a Pandemic at a Less Than Global Scale: Governors Take the Lead. The American Review of Public Administration., 50(6-7), pp. 551-559. doi:10.1177/0275074020941700

CDC (Center for Disease Control), 2020, Coronavirus Disease 2019, https://www.cdc.gov/coronavirus/2019-nCoV/index.html

Cohen, J. and Kupferschmidt, K., 2020, Countries test tactics in 'war'against COVID-19. Science, 367 (6484), pp. 1287-1288, DOI: 10.1126/science.367.6484.1287

Corder, J. K., Mingus, M. S., \& Blinova, D. (2020). Factors motivating the timing of COVID-19 shelter in place orders by U.S. Governors. Policy Design and Practice, 1-16. doi:10.1080/25741292.2020.1825156

Curley, C., and Federman, P., 2020, State Executive Orders: Nuance in restrictions, revealing suspensions, and decisions to enforce. Public Administration Review, 80(4), pp. 623-628. https://doi.org/10.1111/puar.13250.

Curley, Cali and Swann, William L., 2018, Voluntary Compliance in Environmental Programs, in: Saba Siddiki, Salvador Espinosa, and Tanya Heikkila (Eds) Compliance in the Public Sector: Individual Motivations, Social Processes, and Institutional Design, (New York: Routledge). 
Dolowitz, D.P. and Marsh, D., 2000. Learning from abroad: The role of policy transfer in contemporary policy-making. Governance, 13(1), pp.5-23. https://doi.org/10.1111/09521895.00121

Fowler, J.H., Hill, S.J., Levin, R. and Obradovich, N., 2020, The effect of stay-at-home orders on COVID-19 infections in the United States. MedrXiv preprint. doi:

10.1101/2020.04.13.20063628

Fowler, L., Kettler, J., \& Witt, S., 2020. Democratic governors are quicker in responding to the coronavirus than Republicans. The Conversation. Retrieved from https://theconversation.com/democratic-governors-are-quicker-in-responding-to-thecoronavirus-than-republicans-135599

Gallup, 2017, 2017 U.S. Party Affiliation by State. Gallup News, https://news.gallup.com/poll/226643/2017-party-affiliation-state.aspx.

Gandhi, M., Yokoe, D. S., \& Havlir, D. V., 2020. Asymptomatic Transmission, the Achilles' Heel of Current Strategies to Control Covid-19. The New England Journal of Medicine, 382(22), 2158-2160. https://doi.org/10.1056/NEJMe2009758

Gilardi, F. and Wasserfallen, F., 2019. The politics of policy diffusion. European Journal of Political Research, 58(4), pp.1245-1256. https://doi.org/10.1111/1475-6765.12326

Gostin, L.O. and Wiley, L.F., 2020, Governmental public health powers during the COVID-19 pandemic: stay-at-home orders, business closures, and travel restrictions. Jama, 323(21), pp. 2137-2138, https:/jamanetwork.com/journals/jama/fullarticle/2764283.Ferguson and Bowling, 2008

Griffith DM, Sharma G, Holliday CS, Enyia OK, Valliere M, Semlow AR, et al. Men and COVID-19: A Biopsychosocial Approach to Understanding Sex Differences in Mortality and Recommendations for Practice and Policy Interventions. Prev Chronic Dis 2020;17:200247. DOI: http://dx.doi.org/10.5888/pcd17.200247

Halpern, L. W., 2020. The Politicization of COVID-19. The American Journal of Nursing, 120(11), pp.19-20. doi:10.1097/01.NAJ.0000721912.74581.d7

Holley, Cameron, Mutongwizo, Tariro, Pucci, Susan, Castilla-Rho, Juan, and Sinclair, Darren, 2020, Groundwater Regulation, Compliance and Enforcement: Insights on Regulators, Regulated Actors and Frameworks in New South Wales, Australia, in: Jean-Daniel Rinaudo, Cameron Holley, Steve Barnett, and Marielle Montginoul (Eds) Sustainable Groundwater Management: A Comparative Analysis of French and Australian Policies and Implications to Other Countries, (Cham: Springer Nature Switzerland), pp. 411-433.

Howlett, M., 2018. The criteria for effective policy design: character and context in policy instrument choice. Journal of Asian Public Policy, 11(3), pp.245-266. https://doi.org/10.1080/17516234.2017.1412284

Innes, R. and Mitra, A., 2015, Parties, politics, and regulation: Evidence from clean air act enforcement. Economic Inquiry, 53(1), pp. 522-539. https://doi.org/10.1111/ecin.12142.

Kam, C. D., \& Simas, E. N. (2010). Risk orientations and policy frames. The Journal of Politics, 72(2), 381-396. 
Kavanagh, M.M. and Singh, R., 2020, Democracy, Capacity, and Coercion in Pandemic Response-COVID 19 in Comparative Political Perspective. Journal of Health Politics, Policy and Law, 8641530, https://doi.org/10.1215/03616878-8641530.

Klofstad, C.A., Uscinski, J.E., Connolly, J.M. and West, J.P., 2019, What drives people to believe in Zika conspiracy theories?. Palgrave Communications, 5(1), pp.1-8.

Kupferschmidt, K. and Cohen, J., 2020, Can China's COVID-19 strategy work elsewhere?. Science, 367(6482), pp. 1061-1062, DOI: 10.1126/science.367.6482.1061.

Makridis, C. and Rothwell, J.T., 2020. The Real Cost of Political Polarization: Evidence from the COVID-19 Pandemic. Available at SSRN 3638373.

May, P.J. and Winter, S.C., 2011, Chapter 10: Regulatory enforcement styles and compliance, in Christine Parker and Vibeke Lehmann Nielsen (Eds) Explaining compliance: Business responses to regulation, (Northampton: Edward Elgar), pp. 222-244.

Mete, Mihriye, 2002, Bureaucratic Behavior in Strategic Environments: Politicians, Taxpayers and the IRS. Journal of Politics, 64(2): 384- 407. https://doi.org/10.1111/14682508.00131.

Morrow, G., \& Compagni, G. (2020). Mask Mandates, Misinformation, and Data Voids in Local News Coverage of COVID-19. APSA Preprints. doi:10.33774

Nicholson-Crotty, S., 2009. The politics of diffusion: Public policy in the American states. The Journal of Politics, 71(1), pp.192-205. https://doi.org/10.1017/S0022381608090129

Nicholson-Crotty, S. and Carley, S., 2018. Information exchange and policy adoption decisions in the context of US state energy policy. State Politics \& Policy Quarterly, 18(2), pp.122147. https://doi.org/10.1177/1532440018759466

Puhr, R., Heinze, G., Nold, M., Lusa, L., and Geroldinger, A., 2017, Firth's logistic regression with rare events: accurate effect estimates and predictions?. Statist. Med., 36, pp. 23022317, doi: 10.1002/sim.7273.

Pulejo, M., \& Querubín, P., 2020. Electoral concerns reduce restrictive measures during the COVID-19 pandemic (Working Paper 27498), National Bureau of Economic Research.

Radaelli, C.M., 2005. Diffusion without convergence: how political context shapes the adoption of regulatory impact assessment. Journal of european public policy, 12(5), pp.924-943. https://doi.org/10.1080/13501760500161621

Radin, B.A. and Boase, J.P., 2000. Federalism, political structure, and public policy in the United States and Canada. Journal of Comparative Policy Analysis: Research and Practice, 2(1), pp.65-89.

Radin, B.A. and Weimer, D.L., 2018. Compared to what? The multiple meanings of comparative policy analysis. Journal of Comparative Policy Analysis: Research and Practice, 20(1), pp.56-71.

Rai, S., 2020. Policy Adoption and Policy Intensity: Emergence of Climate Adaptation Planning in US States. Review of Policy Research, 37(4), pp.444463.https://doi.org/10.1111/ropr.12383 
Ramírez de la Cruz, E.E., Grin, E.J., Sanabria-Pulido, P., Cravacuore, D. and Orellana, A., 2020, The Transaction Costs of the Governments' Response to the COVID-19 Emergency in Latin America. Public Administration Review, 80 (4), https://doi.org/10.1111/puar.13259. Ringquist, E.J. and Clark, D.H., 2002. Issue definition and the politics of state environmental justice policy adoption. International Journal of Public Administration, 25(2-3), pp.351389. https://doi.org/10.1081/PAD-120013241

Schwartz, J., 2003. The impact of state capacity on enforcement of environmental policies: The case of China. The Journal of Environment \& Development, 12(1), pp.50-Y 81, https://doi.org/10.1177/1070496502250438.

Sherling, D.H. and Bell, M. Masks, 2020. Seat Belts, and the Politicization of Public Health. Journal of Hospital Medicine, 15(11), pp. 692-693. doi:10.12788/jhm.3524

Siddiki, S., Heikkila, T., Weible, C.M., Pacheco-Vega, R., Carter, D., Curley, C., Deslatte, A. and Bennett, A., 2019. Institutional analysis with the institutional grammar. Policy Studies Journal, https://doi.org/10.1111/psj.12361.

Solano, J.J., Maki, D., Adirim, T.A., Shih, R.D., and Hennekens, C.H., 2020. Public health strategies contain and mitigate COVID-19: a tale of two democracies. The American Journal of Medicine. https://doi.org/10.1016/j.amjmed.2020.08.001

Somers, S. and Svara, J.H. (2009), Assessing and Managing Environmental Risk: Connecting Local Government Management with Emergency Management. Public Administration Review, 69: 181-193. https://doi.org/10.1111/j.1540-6210.2008.01963.x

Soss, J., Fording, R. C., \& Schram, S. F. (2008). The color of devolution: Race, federalism, and the politics of social control. American Journal of Political Science, 52(3), 536-553.

Teske, P., 2004, Regulation in the States (Washington DC: Brookings Institution Press).

United States Census Bureau, 2019, Quick Facts, https://www.census.gov/quickfacts/fact/table/US/PST045219.

Tyler, A.L., 2008. Suspension as an Emergency Power. Yale LJ, 118, p.600.

USA Facts, 2020, Coronavirus Locations: COVID-19 Map by County and State. Visualizations, https://usafacts.org/visualizations/coronavirus-covid-19-spread-map/.

Volden, C., 2006. States as policy laboratories: Emulating success in the children's health insurance program. American journal of political science, 50(2), pp.294-312. https://doi.org/10.1111/j.1540-5907.2006.00185.x

Wright, J.E., II and Merritt, C.C., 2020, Social Equity and COVID -19: The Case of African Americans. Public Administration Review, Accepted Author Manuscript, doi:10.1111/puar.13251.

Yilmazkuday, H., 2020, Stay-at-Home Works to Fight Against COVID-19: International Evidence from Google Mobility Data. Available at SSRN 3571708.

Zajenkowski, M., Jonason, P.K., Leniarska, M. and Kozakiewicz, Z., 2020, Who complies with the restrictions to reduce the spread of COVID-19?: Personality and perceptions of the COVID-19 situation. Personality and individual differences, p.110199.

Zelner, B.A. (2009), Using simulation to interpret results from logit, probit, and other nonlinear models. Strat. Mgmt. J., 30: 1335-1348. doi:10.1002/smj.783 
Zheng, Z., Peng, F., Xu, B., Zhao, J., Liu, H., Peng, J., Li, Q., Jiang, C., Zhou, Y., Liu, S. and Ye, C., 2020, Risk factors of critical \& mortal COVID-19 cases: A systematic literature review and meta-analysis. Journal of Infection, https://doi.org/10.1016/j.jinf.2020.04.021 
Table 1: Summary Statistics

\begin{tabular}{|c|c|c|c|c|c|c|}
\hline Frame & Variables & $\mathrm{N}$ & mean & sd & $\min$ & $\max$ \\
\hline DV & Enforcement & 1,361 & $13.7 \%$ & 0.344 & 0 & 1 \\
\hline $\mathrm{C}$ & Gathering Ban & 1,357 & 0.198 & 0.709 & 0 & 3 \\
\hline $\mathrm{C}$ & Stay-at-home Orders & 1,361 & $4.26 \%$ & 0.202 & 0 & 1 \\
\hline $\mathrm{C}$ & Restaurant Closures & 1,361 & $5.44 \%$ & 0.226 & 0 & 1 \\
\hline $\mathrm{C}$ & Gym Closures & 1,361 & $5.73 \%$ & 0.229 & 0 & 1 \\
\hline $\mathrm{C}$ & Self-Care Closures & 1,361 & $2.17 \%$ & 0.145 & 0 & 1 \\
\hline $\mathrm{C}$ & Entertainment Venue Closures & 1,361 & $6.25 \%$ & 0.232 & 0 & 1 \\
\hline $\mathrm{C}$ & Outdoor Recreation Closures & 1,361 & $1.32 \%$ & 0.0930 & 0 & 1 \\
\hline $\mathrm{C}$ & Daycare Closures & 1,361 & $1.65 \%$ & 0.116 & 0 & 1 \\
\hline $\mathrm{C}$ & School Closures & 1,361 & $7.05 \%$ & 0.252 & 0 & 1 \\
\hline $\mathrm{C}$ & Travel Quarantines & 1,361 & 0.0610 & 0.274 & 0 & 2 \\
\hline Risk: + & \% Pop over 65 & 1,361 & $17.1 \%$ & 0.0194 & 0.114 & 0.212 \\
\hline Risk: - & $\%$ Pop Female & 1,361 & $50.6 \%$ & 0.00720 & 0.479 & 0.517 \\
\hline Risk: - & \% Pop White & 1,361 & $78.7 \%$ & 0.113 & 0.255 & 0.944 \\
\hline
\end{tabular}




\begin{tabular}{|c|c|c|c|c|c|c|}
\hline Risk: + & \% Pop High School + & 1,361 & $89.3 \%$ & 0.0281 & 0.829 & 0.932 \\
\hline Risk: + & Median HH Income & 1,361 & 61,466 & 10,298 & 43,567 & 81,868 \\
\hline Political: - & \% Registered Republicans & 1,361 & $39.21 \%$ & 7.207 & 26 & 56 \\
\hline Risk: + & Confirmed Cases (lag) & 1,361 & 6,457 & 15,437 & 0 & 202,208 \\
\hline Risk: + & Gov Female & 1,361 & $16.9 \%$ & 0.375 & 0 & 1 \\
\hline Political: - & Competitive Politics & 1,361 & $28.4 \%$ & 0.451 & 0 & 1 \\
\hline Political: + & Gov Reelection Years Away & 1,361 & 1.655 & 0.858 & 0 & 3 \\
\hline Political: - & Gov Eligible for Reelection & 1,361 & $67.7 \%$ & 0.468 & 0 & 1 \\
\hline Political: - & Republican & 1,361 & $50.2 \%$ & 0.500 & 0 & 1 \\
\hline
\end{tabular}

Table 2: Probit Model with State Clustered Standard Errors

\begin{tabular}{lcc}
\hline Variables & Full Model & Frames \\
\hline Gov Eligible for Reelection & -0.333 & -0.298 \\
& $(0.267)$ & $(0.244)$ \\
Gov Reelection Years Away & $-0.359^{* *}$ & $-0.288^{*}$ \\
& $(0.162)$ & $(0.149)$
\end{tabular}


Competitive Politics

Republican

\% Registered Republicans

Govern Female

\% Pop Age Over 65

$\%$ Pop Female

\% Pop White

\% Pop High School +

Median HH Income

$$
\begin{array}{cc}
0.579 * * & 0.537 * * \\
(0.257) & (0.239)
\end{array}
$$

$$
\begin{array}{cc}
-0.637 * * * & -0.611 * * * \\
(0.200) & (0.186)
\end{array}
$$

$\begin{array}{ll}-0.00418 & 0.00361\end{array}$

$(0.0263) \quad(0.0240)$

$0.469 \quad 0.357$

$\begin{array}{ll}(0.285) & (0.229)\end{array}$

$\begin{array}{ll}-9.926 & -6.231\end{array}$

(7.590) (6.407)

$14.88 \quad 12.81$

(18.22) (16.61)

$-1.539-2.244 * * *$

(1.030) (0.839)

$-0.0745 \quad 1.369$

(5.918) (5.640)

1.31e-05 7.88e-06 
(1.93e-05) (1.81e-05)

Confirmed Cases (lag)

Stay-at-home Orders

Restaurant Closures

Gym Closures

Self-Care Closures

Entertainment Venue Closures

Outdoor Recreation Closures

Daycare Closures
$0.443 *$

$(0.251)$

$0.913 * * *$

(0.333)

$2.64 \mathrm{e}-06 \quad 2.45 \mathrm{e}-06$

(3.62e-06) (2.86e-06)

$3.86 \mathrm{e}-05^{* * *}$

$(1.20 \mathrm{e}-05)$

$-0.201$

$(0.252)$

$0.714 * *$

(0.289)

0.00690

$(0.315)$

$0.715^{* *}$

(0.346) 
School Closures

Travel Quarantines

Gathering Ban

Constant

Observations
0.196

$(0.195)$

$0.907 * * *$

(0.226)

$0.230 * * *$

$(0.0774)$

$-5.841 \quad-5.938$

(11.41) (10.72)

$.2178 \quad .0931$

$1,357 \quad 1,361$

Standard errors in parentheses

$* * * \mathrm{p}<0.01, * * \mathrm{p}<0.05, * \mathrm{p}<0.1$ 